\title{
UMBANDA ESOTÉRICA: UMA ETNOGRAFIA SOBRE O ENCONTRO DA RELIGIOSIDADE AFRO COM A NOVA ERA EM UM TERREIRO DE BELO HORIZONTE
}

\author{
Bianca Zacarias França ${ }^{1}$ \\ DOI 10.26512/revistacalundu.v3i2.27048
}

\begin{abstract}
Resumo
No campo dos estudos religiosos, observa-se uma falta da produção acadêmica que busque compreender o espaço ocupado pelas religiões afro no contexto Nova Era. Autores como Magnani (2000) e Amaral (2000) entendem a Nova Era como um movimento intimamente influenciado pelo ocultismo europeu, Transcendentalismo americano do século XIX, teosofia de Helena Blavastsky, Espiritualismo, New Thought e Christian Science. O movimento Nova Era, em seu aspecto histórico, começou nos anos 60 e 70 em um contexto de contracultura e um fluxo crescente de intercâmbio entre Oriente e Ocidente (AMARAL, 2000). Este movimento apresenta "um amplo leque de interesses, passando pela religião, filosofia, misticismo, saúde, psicologia, parapsicologia, arte, ecologia e o oculto" (AMARAL, 2000, p.29). Outros estudiosos da religião como o antropólogo Silas Guerriero (2006) já enquadram a Umbanda Esotérica dentro da categoria de Novos Movimentos Religiosos e Nova Era, afirmando que, apesar de recente, doutrinas como essa buscam um vínculo com religiões e doutrinas muito antigas como o hinduísmo e o próprio catolicismo. Há um entendimento de que, no Brasil, a Nova Era possui suas singularidades e que por isso doutrinas como a Umbanda Mística, as religiões ayahuasqueiras e o Vale do Amanhecer, por exemplo, podem ser entendidas como manifestações da New Age Popular (OLIVEIRA, A., 2009). Dessa forma, este trabalho também se propõe a pensar a Umbanda Esotérica, considerando as singularidades desta doutrina no contexto brasileiro.
\end{abstract}

Palavras-chave: Umbanda Esotérica. Religiosidade Afroindígena. Nova Era. Antropologia da Religião.

\section{UMBANDA ESOTÉRICA: UNA ETNOGRAFÍA PARA REUNIRSE DESDE LA RELIGIOSIDAD CON LA NUEVA EDAD EN UNA TERRAZA BELO HORIZONTE}

\section{Resumen}

En el campo de los estudios religiosos, existe una falta de producción académica que busque comprender el espacio ocupado por las religiones afro en el contexto de la

\footnotetext{
${ }^{1}$ Universidade Federal de Minas Gerais.
} 
Nueva Era. Autores como Magnani (2000) y Amaral (2000) entienden la Nueva Era como un movimiento íntimamente influenciado por el ocultismo. Transcendentalismo estadounidense del siglo XIX, Teosofía, Espiritualismo, Nuevo Pensamiento y Ciencia Cristiana de Helena Blavastsky. El movimiento New Age, en su aspecto histórico, comenzó en los años 60 y 70 en un contexto de contracultura y un creciente flujo de intercambio entre Oriente y Occidente (AMARAL, 2000). Este movimiento presenta "una amplia gama de intereses, desde religión, filosofía, misticismo, salud, psicología, parapsicología, arte, ecología y ocultismo" (AMARAL, 2000, p.29). Otros eruditos religiosos como el antropólogo Silas Guerriero (2006) ya encajan en Umbanda Esotérica dentro de la categoría de Nuevos movimientos religiosos y Nueva era, afirmando que aunque recientes, doctrinas como esta buscan un vínculo con religiones y doctrinas muy antiguas como el hinduismo y El catolicismo mismo. Se entiende que, en Brasil, la Nueva Era tiene sus singularidades y, por lo tanto, doctrinas como la Mística Umbanda, las religiones de Ayahuasqueiras y el Valle del Amanecer, por ejemplo, pueden entenderse como manifestaciones de la Nueva Era Popular (OLIVEIRA, A ., 2009). Por lo tanto, este trabajo también tiene la intención de pensar en la Umbanda Esotérica, considerando las singularidades de esta doctrina en el contexto brasileño.

Palabras-Clave: Umbanda Esotérica. Religiosidad afro-indígena. Nueva Era. Antropología de la Religión.

\section{O trabalho de campo}

Este artigo compõe um processo de pesquisa de caráter etnográfico mais amplo que se iniciou no segundo semestre de 2014 no Templo Universalista e Espiritualista Solar - TUÉS, um terreiro de Umbanda Esotérica localizado na região central da cidade de Belo Horizonte. O terreiro foi criado no dia 13 de maio de 2009 por Luís Gustavo, chefe da casa, com o apoio de sua família.

A partir de 2014, comecei a frequentar a casa enquanto médium neófita/ médium em provas. No segundo semestre de 2015, passei pelo ritual de aceitação do terreiro e de fato comecei a fazer parte da corrente mediúnica. Dessa forma, pude participar de diversos ritos públicos, ritos internos, três ritos de aceitação, vivências e aulas no terreiro até o momento presente em que escrevo este artigo. Além disso, o trabalho também foi permeado e enriquecido por conversas informais e entrevistas com membros e membras iniciados e não iniciados do terreiro. Entrevistas estas menos com caráter extrativo de informações e mais como um espaço de trocas e narrativas vivas que perpassam a vida destes umbandistas.

Marilyn Strathern (2014) levanta a questão preliminar de como se conhece quando se está em casa, ou seja, o fazer antropológico realizado no mesmo contexto 
social que o produziu. Estaria uma umbandista que estuda com outros umbandistas em casa? Para a autora, questões como essa não se relacionam à familiaridade ou à distância, mas o que realmente importa é saber se investigadora-investigados estão igualmente em casa, compartilhando conceitos, premissas e entendimentos sobre a vida social.

Neste processo de imersão etnográfica dialógica, engajada e ativa, utilizando este espaço como fonte de dados e feitura do conhecimento, considerei a ideia de pesquisadora cambona (SIMAS; RUFINO, 2018). Mais do que ser uma cambona em si, o intento foi realizar a pesquisa com a atitude de uma cambona, entendendo esse saber/fazer como inacabado e vivo.

...o cambono é uma espécie de auxiliar de pai de santo e das próprias entidades que, ao mesmo tempo, atua como um " faz tudo" no terreiro: ele varre o salão, acende o cachimbo da vovó, sustenta o verso nos corridos, organiza a assistência, auxilia os consulentes, despacha a entrada, opera como tradutor nas consultas, registra o receituário, toma bronca e é orientado. Sem delongas, o cambono firma ponto e segura a pemba em um terreiro.

A figura do cambono, como símbolo que compreende uma série de fazeres/saberes, é potente para pensarmos a atitude do pesquisador que se orienta pelos saberes assentados nas epistemologias das macumbas. O cambono é aquele que se permite afetar pelo outro e atua em função do outro. No desempenho de suas atividades, participa ativamente das dinâmicas de produção e circulação de saberes. Assim, o cambono é aquele que opera, na interlocução, com todas as atividades que precedem os fazeres/saberes necessários para as aberturas de caminhos. (SIMAS; RUFINO, 2018, p.36)

A pesquisadora cambona, então, participa ativamente de processos de transformação e mediação tanto no terreiro quanto na pesquisa. Portanto, este projeto, não se trata de uma mera compreensão do religioso, porque se assim o fosse correria o sério risco de destruir a experiência (SEGATO, 1992). Por fazer parte do TUÉS, a grande contribuição não é acessar algo interno que alguém de fora não poderia, mas sim a própria experiência religiosa. Mais do que levar e trazer informações, é a mediação, que está também relacionada à minha própria experiência, que contribui para o pensar. Este é de fato um projeto cheio de riscos, mas que gera um lugar de fala potencialmente rico. Dessa forma, peço agô ${ }^{2}$ para começar...

\footnotetext{
${ }^{2}$ Expressão usada por muitas religiosidades afro-brasileiras como sinal de respeito e para pedir permissão e licença para o início de um trabalho espiritual.
} 


\title{
Introdução
}

As religiões afro-brasileiras possuem uma matriz que se relaciona

\begin{abstract}
a um conjunto algo heteróclito, mas certamente articulado, de práticas e concepções religiosas cujas bases foram trazidas pelos escravos africanos e que, ao longo da sua história, incorporaram em maior ou menor grau elementos das cosmologias e práticas indígenas, assim como do catolicismo popular e do espiritismo de origem europeia. Evidentemente, esses elementos transformam-se à medida que são combinados, e vice-versa. (GOLDMAN, 2009, p. 106)
\end{abstract}

Os estudos da área da antropologia que se debruçam sobre essas religiões podem ser divididos em dois períodos: um culturalista/evolucionista e outro que parte de uma perspectiva mais sociológica (BANAGGIA, 2008; GOLDMAN, 2009). O primeiro período, que ocorreu do final do século XIX ao início dos anos 1970, é caracterizado por estudos que buscavam "sobrevivências africanas" nas religiões afro-brasileiras, descrevendo seu sistema de culto, mitologia, símbolos e rituais. O objetivo era entender a origem dos itens estudados e sua classificação nos diferentes graus de desenvolvimento da visão evolucionista. São autores deste período, por exemplo, Nina Rodrigues e Arthur Ramos, que focaram seus estudos principalmente na região Norte e Nordeste do país. O segundo período, que começou na década de 1970 e tem repercussões até a atualidade, se formou como uma crítica aos primeiros estudiosos do campo e teve forte influência da antropologia social britânica e da sociologia francesa de Bourdieu. Estes estudos estão contextualizados na região sudeste do país, principalmente nos estados de São Paulo e Rio de Janeiro. Buscam entender a relação dos terreiros com a dita sociedade envolvente, considerando disputas por poder, classe, processos de urbanização/industrialização e a organização social. São autoras reconhecidas deste contexto Yvonne Maggie, Beatriz Góis Dantas, Stefania Capone, Diana Degroat Brown, Patrícia Birman (BANAGGIA, 2008; GOLDMAN, 2009).

No campo dos estudos religiosos, observa-se uma falta da produção acadêmica que busque compreender o espaço ocupado pelas religiões afro no contexto Nova Era. Autores como Magnani (2000) e Amaral (2000) entendem a Nova Era como um movimento intimamente influenciado pelo ocultismo europeu, Transcendentalismo 
americano do século XIX, teosofia de Helena Blavastsky ${ }^{3}$, Espiritualismo, New Thought e Christian Science. O movimento Nova Era, em seu aspecto histórico, começou nos anos 60 e 70 em um contexto de contracultura e um fluxo crescente de intercâmbio entre Oriente e Ocidente (AMARAL, 2000). Foi neste período que muitos gurus missionários migraram para os Estados Unidos e Europa para difundir suas práticas. Houve uma grande apropriação de filosofias e religiões orientais, da Renascença Hindu e de povos indígenas, sendo uma característica desse movimento "o discurso de autodesenvolvimento, na base das propostas terapêuticas atraídas por experiências místicas e filosofias holistas, fazendo-as corresponder às modernas teses de divulgação científica" (AMARAL, 2000, p.32). É neste contexto que obras como O Tao da Física e Ponto de Mutação de Fritjof Capra (1974) são lançadas. A Nova Era tem como tendência e pilar a transformação de si para assim transformar toda a humanidade. Apresenta "um amplo leque de interesses, passando pela religião, filosofia, misticismo, saúde, psicologia, parapsicologia ${ }^{4}$, arte, ecologia e o oculto" (AMARAL, 2000, p.29).

Há um entendimento de que, no Brasil, a Nova Era possui suas singularidades e que por isso doutrinas como a Umbanda Mística, as religiões ayahuasqueiras e o Vale do Amanhecer, por exemplo, podem ser entendidas como manifestações da New Age Popular (OLIVEIRA, A., 2009). Dessa forma, penso que a Umbanda Esotérica também possa ser enquadrada nesta categoria de New Age Popular. Essa doutrina tem como característica uma íntima relação com a ciência e com religiosidades orientais, como é próprio do movimento Nova Era, e possui suas especificidades por fazer parte do contexto brasileiro.

O que denominamos New Age Popular, que vem a ser uma nova releitura, a partir de um contexto social próprio, de práticas e de tradições culturais originadas no Brasil e no exterior - entre as quais, a umbanda, elementos da religiosidade popular, o espiritismo kardecista e, o catolicismo popular, principalmente - nos moldes típicos da New Age, que recria aspectos culturais - como os rituais, principalmente os de possessão, das religiões populares no Brasil, além do aspecto estético -, que até então, não haviam sido enfatizados pelo movimento. (OLIVEIRA, A., 2009, p.39)

\footnotetext{
${ }^{3}$ Helena Petrovna Blavastsky foi uma esotérica russa que fundou a sociedade teosófica em 1875 e causou grande impacto na comunidade científica e esotérica da época ao publicar seu primeiro livro Ísis Sem Véu, atribuindo sua autoria a seus mentores orientais (CORDOVIL; CASTRO, 2018).

4 Parapsicologia é a ciência que estuda eventos tidos como paranormais, transcendentais ou metapsíquicos, estudando fenômenos como a mediunidade e ocorrências ligadas a ela.
} 
O termo New Age Popular chama atenção para o fato de que a Nova Era tem raízes europeias e norte-americanas e que, no Brasil, existe uma forte valoração, mesmo que com apropriações diversas, de elementos das religiosidades populares, como os cultos afro-brasileiros (OLIVEIRA, A., 2009).

Alguns membros do TUÉS entendem a Umbanda Esotérica e a própria Umbanda de forma geral como parte do movimento Nova Era, porque esta tem, para eles, uma origem tão antiga quanto a própria formação da Terra. Carolina Lopes, iniciada de primeiro grau da casa, em uma conversa informal, fez íntima relação entre a Umbanda Esotérica e a Nova Era:

Eu entendo sim que a Umbanda Esotérica é um movimento da Nova Era e percebo que todas essas linhas que estão chegando com essa força universalista, que tem um discurso de não preconceito, um discurso não exclusivo, de receber qualquer tipo de alma, qualquer tipo de credo religioso e de não se colocar como uma religião principalmente, para mim, são movimentos da Nova Era... Eu sinto que a Nova Era é a era da unidade...uma era em que a separação e o individualismo estão sendo deixados de lado,... onde as pessoas estão percebendo que o sistema que a gente está vivendo há muitos e muitos já está falho... é um movimento contra esse sistema capitalista, patriarcal, separatista... A Nova Era vem trazendo o ser humano como unidade, sem falar de línguas, de povos, nações e, nesse sentido, eu me identifico muito nas palestras do Luís Gustavo no terreiro quando ele sempre fala do universalismo, de receber qualquer pessoa que quer se curar... quando ele fala na oração uma só língua, um só povo, uma só nação (Carolina Lopes, TUÉS, 2019).

Esta fala da iniciada nos revela a estreita relação entre Nova Era e o Universalismo presentes no TUÉS. Carolina também faz referência à oração de saudação ao Universalismo que, muitas vezes, é feita pelo sacerdote Luís Gustavo para a abertura dos ritos no terreiro, pedindo por: "um só planeta, uma só pátria, sem fronteiras, uma só língua, uma só energia...”. O Universalismo aparece como uma característica da própria Umbanda e do umbandista que não são entendidos como religião, mas de uma doutrina ou filosofia de vida. Dessa maneira, a espiritualidade seria algo universal que se manifesta de formas específicas em cada contexto.

Muitos acadêmicos defendem a tese de que a Umbanda se define como corpo religioso a partir da década de 1930 no contexto de urbanização do Brasil e transição de uma estrutura agrária para uma urbano-industrial (JORGE ET AL., 2016). Entretanto, para este grupo, o Aumbhandhan surgiu entre 10 e 15 mil anos atrás. Esse é um período que remete ao contexto da Lemúria, entendido por muitos como o continente perdido. Hipóteses sobre a formação das civilizações na Terra estão ligadas a esse continente. 
Ele seria formado por uma parte do que hoje é a África, Ásia e América. Diversas vezes, nas palestras que antecedem os ritos públicos, nomeadas como prédicas, o chefe do terreiro afirmou que o ritual que estava prestes a acontecer ali seria uma reprodução dos cultos que ocorriam na Atlântida antiga. O que rege todas as mudanças na Terra, de acordo com essa linha religiosa, desde seu início, é o Aumbhandan ou Conjunto das Leis Divinas que em um período posterior, por meio de uma revelação espiritual, passaria a ser chamado de Umbanda. Esse termo, Umbanda, é considerado a palavra perdida.

A Lemúria, neste entendimento, se encontra no contexto da Pangeia, remetendo a teoria científica que afirma que, nos períodos iniciais de formação da Terra, todos os continentes estariam juntos. A oração de saudação ao universalismo durante os ritos, segundo Luís Gustavo, faz referência a este passado da Pangeia e ao futuro no qual os continentes voltarão a se unir.

Em entrevista, Luís Gustavo esclareceu o motivo de o terreiro carregar em seu nome o termo "universalista":

As regras são criadas por nós aqui humanos. Isso sempre me atraiu muito: o que o espírito que segue na umbanda vai falar, vai dizer, vai apontar. E tive algumas experiências que eu perguntava para os espíritos se eles eram umbandistas e eles sempre respondiam: "' Também! Também sou umbandista". Então, minha ficha foi caindo que umbanda, catolicismo, hinduísmo, protestantismo são coisas aqui da Terra. O universo é muito mais amplo do que isso. Então, quando fomos dar nome ao templo, nós tentamos encaixar o nome a percepção que eu tenho de religião ou de religiosidade que são duas coisas diferentes. Religião é aquela coisa conceitual. Religiosidade é a prática que você aprende, a essência de uma religião... E tive a felicidade de encontrar com uma iniciada do pai Matta, através da mãe velha que a assiste, que abonou esse nome e a proposta que eu tinha colocado de que o universalismo fosse a bandeira não só da umbanda mas do aumbhandan. E engraçado que o universalismo já está em outras religiões, mas as pessoas não percebem. O termo católico significa, traduzindo do latim, aquele que é universal. As igrejas evangélicas usam sempre o nome "universal". (Grifo nosso) (Luís Gustavo, TUÉS, 2016).

Silas Guerriero (2006) enquadra a Umbanda Esotérica dentro da categoria de Novos Movimentos Religiosos e Nova Era, afirmando que, apesar de recente, segmentos religiosos como este buscam legitimidade por meio do vínculo com religiões e doutrinas muito antigas como o hinduísmo e o próprio catolicismo. É importante pontuar que análises com tom sociológico como estas, muitas vezes, dão a impressão que os fiéis executam um cálculo utilitarista para disputar com mais eficiência um 
mercado religioso e atrair mais membros. Dessa forma, a religião é entendida como uma metáfora das relações sociais e dos conflitos que as permeiam. Para Luís Gustavo, sacerdote do TUÉS, a Umbanda Esotérica não compõe o gradiente de religiões da Nova Era porque esta não busca vínculos com religiões antigas, ao contrário, é de fato uma das doutrinas mais antigas da Terra.

Esse aspecto universal não indicaria que a Umbanda deixou de ter um caráter étnico para disputar adeptos no mercado religioso, como indica Prandi (1991) em seus estudos sobre o Candomblé em São Paulo. A Umbanda possibilita a presença de diferentes elementos das mais diversas religiões como o budismo, o hinduísmo, o catolicismo, o taoísmo, o Santo Daime, tradições esotéricas como a Rosa Cruz Áurea, por exemplo. Para frequentar o terreiro, dessa forma, não há exigência de conversão, permitindo que o indivíduo possa ter uma múltipla pertença religiosa e mais do que isso, possa ser universalista.

Entretanto, isso não significaria que os membros do TUÉS não possuem uma identidade ou fidelidade religiosa. No período das festividades juninas do ano de 2019, uma das médiuns da casa postou por três dias seguidos, em um grupo de uma rede social exclusiva para os membros do TUÉS, orações referentes à novena de Santo Antônio de Pádua e, no terceiro dia de postagens, o sacerdote da casa questionou se a Igreja Católica também recomendava trabalhos de Umbanda para os seus fiéis. A médium concordou e disse que acreditava no Universalismo da Umbanda. Com isso, o líder espiritual também afirmou acreditar no universalismo e que por isso protegia a Umbanda em relação ao sincretismo, uma vez que este teria acarretado perdas e ignorâncias relativas a esta doutrina religiosa. Outro médium concluiu que a situação o lembrava da época do Padre Anchieta e a catequização indígena, postando, na rede social do terreiro, a música Cordeiro de Nanã do grupo musical popular no Brasil nos anos 60 e 70, “Os Ticoãs". A letra da canção faz alusão ao período colonial brasileiro, no qual negros escravizados eram forçados a aderir ao catolicismo e abdicar de sua fé aos orixás, voduns, inkices.

Fui chamado de cordeiro mais não sou cordeiro não

Preferir ficar calado que falar e levar não

O meu silêncio é uma singela oração a minha santa de fé

Meu cantar vibram as forças que sustentam meu viver

Meu cantar é um apelo que eu faço a nanã ê

SOU DE NANÃ Ê UÁ Ê UÁ Ê UÁ Ê (3X)

O que peço no momento é silêncio e atenção

Quero contar sofrimento que passamos sem razão 
O meu lamento se criou na escravidão que forçado passei

Eu chorei sofri as duras dores da humilhação

Mas ganhei pois eu trazia nanã ê no coração (Os Ticoãs, Cordeiro de

Nanã, 1977).

Luís Gustavo concluiu a conversa dizendo: 'Precisamos ter uma identidade. O Universalismo é a soma das diferenças e não fusão de várias crenças". Nessa perspectiva, o universalismo funciona como um grande encontro como proposto por Stengers (2018): não é necessariamente harmônico, exige a não existência de uma hierarquia e uma coaprendizagem recíproca que não inclui obrigatoriamente a coincidência. Como um acontecimento cósmico, este encontro é capaz de acontecer entre forças divergentes, não sendo necessário suspender essa heterogeneidade.

$\mathrm{O}$ argumento utilizado pelo líder do terreiro para argumentar contra o sincretismo é similar às ideias apresentadas no manifesto contra o sincretismo assinado, nos anos 80, por cinco grandes lideranças religiosas do Candomblé de Salvador: as ialorixás Mãe Menininha do Terreiro do Gantois, Mãe Stella de Oxóssi do Ilê Axé Opô Afonjá, Mãe Olga do Terreiro do Alaketu, Mãe Tetê de Iansã do Terreiro da Casa Branca e a Doné Mãe Nicinha do Terreiro do Bogum. Neste manifesto as lideranças se posicionavam contra o sincretismo entre as divindades dos Candomblés e os santos da Igreja Católica. Este, na época, obteve bastante visibilidade através da mídia e foi amplamente discutido por adeptos e acadêmicos. Flaksman cita um dos trechos do documento citados:

Vinte e sete de julho passado deixamos pública nossa posição a respeito do fato de nossa religião não ser uma seita, uma prática animista primitiva; consequentemente, rejeitamos o sincretismo como fruto da nossa religião, desde que ele foi criado pela escravidão à qual foram submetidos nossos antepassados. (...) Vemos que todas as incoerências surgidas entre as pessoas do candomblé que querem ir à lavagem do Bonfim carregando suas quartinhas, que querem continuar adorando Oyá e Santa Bárbara, como dois aspectos da mesma moeda, são resíduos, marcas da escravidão econômica, cultural e social que nosso povo ainda sofre. Desde a escravidão que preto é sinônimo de pobre, ignorante, sem direito a nada; e por saber que não tem direito é um grande brinquedo dentro da cultura que o estigmatiza, sua religião também vira brincadeira. (...) Durante a escravidão, o sincretismo foi necessário para a nossa sobrevivência, agora, em suas decorrências e manifestações públicas, gente do santo, ialorixás, realizando lavagens nas igrejas saindo das camarinhas para as missas etc., nos descaracteriza como religião, dando margem ao uso da mesma coisa exótica, folclore, turismos. Que nossos netos possam se orgulhar de pertencer à religião de seus antepassados, que ser preto, negro, lhes traga de volta a África e não a escravidão. (...) Todo este nosso 
esforço é por querer devolver ao culto dos Orixás, à religião africana, a dignidade perdida durante a escravidão e processos de correntes da mesma: alienação cultural, social e econômica, que deram margem ao folclore, ao consumo e profanação da nossa religião (p.5, 2017).

Tanto o posicionamento das Mães Baianas quanto do líder do TUÉS evidencia um rompimento com um certo regime de identificação que impede que a dimensão afroindígena religiosa possa ser valorizada. Não é exatamente uma recusa ao catolicismo, mas mostrar, assim como Bastide (1973), que o catolicismo pode ser mais uma nação do Candomblé e ser africanização por ela, ao invés de ser entendido como um fator de desafricanização e descaracterização.

Neste sentido, o universalismo presente no TUÉS se aproximaria mais ao que Veras (2018) chamou de pluralismo religioso, no qual a composição ritual nos mostra como é possível agregar em um mesmo agenciamento Nossa Senhora, Jesus e entidades. Da mesma forma que no contexto estudado por Veras (2018), os membros do TUÉS não entendem como um problema o fato de alguém se tornar evangélico, por exemplo. Isto não impediria sua presença no terreiro ou que este indivíduo frequentasse os ritos.

O sacerdote do TUÉS, por vezes, repetiu a seguinte frase desde que pude acompanhar a trajetória do terreiro a partir de 2014: "a Umbanda é para todos, mas nem todos são para a Umbanda". Ser umbandista, desta forma, está atrelado a uma condição de nascimento e, neste ponto de vista, não há a existência de uma conversão religiosa, mas o reconhecimento de sua própria natureza, do seu próprio estado. Sobre isso a médium Verônica colocou:

Eu descobri a Umbanda como uma forma de vida mesmo... como um estilo de vida universal. Muitas coisas que eu hoje vejo na Umbanda, eu consigo enxergar em outras vertentes. Não acho que é uma religião, uma coisa fechada... algo que tenha um livro sagrado para a gente seguir. Eu descobri mesmo. Nasci para aquilo. É realmente uma coisa que te atrai. É sagrado. Principalmente em relação ao autoconhecimento, me enxergar... tudo que eu não podia associar a mim, porque era pecado ou porque era do demônio. Eu tive a oportunidade de me conhecer.

Mesmo possuindo um caráter universalizante em sua cosmologia,

o destino que leva alguns, e só alguns, a iniciar-se nos terreiros, assim mesmo os distingue. De um lado, uma postulação amplamente inclusiva; de outro, um princípio de determinação exclusiva (a separar iniciados e profanos). Mas eles se equilibram e se complementam. (Serra, 1995, p.19) 
Serra (1995) coloca a Umbanda como uma exemplo de ecletismo religioso, ou seja, uma "espécie de doutrina que é expressamente elaborada com o propósito de realizar a síntese de várias, senão de todas as religiões" (p. 14). Mesmo possuindo de fato essa característica sintética, acredito que a Umbanda também pode abarcar o que o autor chama de "pluralismo religioso de princípio": há um reconhecimento da legitimidade religiosa de outras doutrinas, sem que se perca a singularidade ritual, "descrevendo a dedicação ao mesmo como uma necessidade imposta a determinadas pessoas (ou grupos) por Deus, pelos orixás, pelo destino" (p.15).

Para Carneiro da Cunha (1987), não basta que o Deus de uma religião seja universal para que esta também seja considerada desta forma. A autora caracteriza duas formas de religião: uma baseada em um deus exclusivo que não discrimina os fiéis e outra simétrica na qual o grupo de culto é exclusivo, "pois seu deus é bem seu, mas por isso mesmo 'não exclui a possibilidade de outros deuses, tão específicos quanto ele próprio. Sua Igreja é coextensiva ao grupo social" " (Serra, 1995, p.27).

No altar do TUÉS, não existem imagens (nem de orixás ou santos), apenas um quadro fixado na parede com o rosto de Jesus em preto e branco. Este foi afixado no ano de 2018 como símbolo do quarto grau de iniciação de Luís Gustavo. Segundo o sacerdote, esta imagem é como uma fotografia, uma recordação de um bom exemplo e do caminho que devemos seguir. Na mesma época, 7 taças redondas de água foram colocadas, formando um círculo entorno da vela localizada no centro do altar. Cada uma delas contém a vibração dos Sete Orixás Maiores para a Umbanda Esotérica: Xangô, Oxossi, Yori, Yorimá, Oxalá, Ogum e Yemanjá. Este altar é significativo para manifestar a energia de um Deus realmente universal e sem imagens, ou melhor, que contenha todas as imagens e que acolha a todos.

Nesse sentido, Neto (2007, p.121), que foi um dos principais expoentes da Umbanda Esotérica no Brasil, afirma que:

o verdadeiro umbandista é universalista, não no sentido de fazer uma "grande mistura", mas no sentido de entender as misturas e os vários entendimentos que se encontram dentro delas. Assim, quanto mais dissermos que somos religiosos, menos nos encontraremos próximos da verdade, e sim cada vez mais distantes dela. O verdadeiro Umbandista não é só religioso, é ligado às Filosofias, às Ciências e às Artes.

Alguns segmentos umbandistas, como é o caso do grupo mediúnico do TUÉS, atribuem à figura de Zélio Fernandino de Moraes um status privilegiado na história 
umbandista. Nas aulas dadas no terreiro e nas obras estudadas pelos médiuns, é reforçada a ideia de que a Umbanda ressurge no Rio de Janeiro em 1908 com Zélio Fernandino. Conta-se que Zélio é natural de São Gonçalo no Rio de Janeiro e aos 17 anos, quando se preparava para os exames da Escola Naval, foi acometido por uma estranha paralisia. Nenhum médico conseguia identificar o que estava acontecendo com o rapaz: dizia palavras desconexas, tinha visões e aparente perturbação mental. Zélio anunciou que ficaria curado e no dia seguinte ao anúncio assim se fez. Entretanto, a confusão mental ainda permanecia o que fez com que sua família muito católica o encaminhasse para um padre a fim de que fosse exorcizado. $O$ feito também não foi bem sucedido. Então, Zélio foi levado à Federação Espírita do Estado do Rio de Janeiro que se localiza em Niterói.

Na Federação, durante uma sessão espírita, no dia 15 de novembro de 1908, o jovem rapaz incorporou a entidade conhecida como Caboclo das Sete Encruzilhadas. Um médium vidente questionou o Caboclo das Sete Encruzilhadas, dizendo que estava vendo ali, na verdade, um sacerdote católico. E o Caboclo de fato confirmou que era uma encarnação do Padre Gabriel de Malagrida. Afirmando que ali estava faltando uma flor, o Caboclo vai até o jardim da Federação e volta, colocando uma flor em cima da mesa. Outros médiuns que estavam no local manifestavam espíritos de negros escravos (entidades conhecidas como Pretos-Velhos) e índios (entidades conhecidas como Caboclos), sendo que as entidades juntamente com Zélio Fernandino e o Caboclo das Setes Encruzilhadas foram convidadas pelo dirigente da reunião a se retirarem do local por serem consideradas espiritualmente atrasadas. O Caboclo das Sete Encruzilhadas discursava em favor daquelas entidades que segundo ele estavam sendo discriminadas por sua cor e classe social. Assim, o Caboclo disse que no dia seguinte seria formada uma nova religião, a religião de Umbanda, com um rito inicial na casa de Zélio onde todas as entidades que não poderiam se manifestar naquele local (a Federação) teriam liberdade para expressarem suas mensagens e realizarem seus trabalhos espirituais.

No dia seguinte, 16 de novembro de 1908, às 20h, em meio a uma pequena multidão de curiosos, parentes e céticos, o Caboclo das Sete Encruzilhadas incorporado em Zélio Fernandino declara que na religião de Umbanda os Pretos Velhos e os Caboclos seriam livres para trabalhar. Além disso, determinou algumas regras como o uso de roupas brancas por parte dos médiuns durante os ritos, a prática da caridade, não cobrar por nenhum atendimento espiritual, se basear no Evangelho Cristão e o não sacrifício de animais. Dessa forma, na Rua Floriano Peixoto, no 30, no bairro de Neves, 
em São Gonçalo, Rio de Janeiro, surge, de acordo com algumas correntes umbandistas (incluída a Umbanda Esotérica), a primeira tenda de Umbanda, a Tenda Espírita Nossa Senhora da Piedade. A Tenda, ainda hoje em funcionamento, agora está situada no município de Cachoeiras do Macacu, Estado do Rio de Janeiro. Dez anos depois de sua fundação, conta-se que o Caboclo das Sete Encruzilhadas teria determinado a criação de sete novas casas de Umbanda: São Pedro; Nossa Senhora da Guia; Nossa Senhora da Conceição; São Jerônimo; São Jorge; Santa Bárbara; e Oxalá. Essas tendas seriam as responsáveis por uma maior propagação da nova religião.

Para Giumbelli (2002), o reconhecimento de Zélio Fernandino é uma construção tardia, aparecendo apenas em trabalhos acadêmicos posteriores a 1960. Seria apenas na década de 70 que o Conselho Deliberativo da Umbanda - CONDU - afirmaria o dia 15 de novembro como dia nacional da Umbanda.

Longe de um consenso, tal reconhecimento da figura de Zélio aponta para um projeto federativo específico que procura generalizar o que tende a permanecer uma consagração restrita a certo segmento do universo umbandista"' (GIUMBELLI, 2002, p. 195).

Para Serra (2014), o que é tido como a origem da Umbanda e o advento de Zélio Fernandino de Moraes é na verdade uma reforma desafricanizante desta religião, uma vez que a Umbanda teria originalmente uma raiz afro. Afasta-se desta raiz em detrimento da defesa da Umbanda como uma religião brasileira. Se para Ortiz (1978) o movimento de branqueamento é uma transformação histórica, evolucionista e irreversível, para Serra (2014) existe um embate entre a reafricanização e desafricanização que são forças que atuam mutuamente neste contexto.

15 de novembro também é a data em que se comemora no Brasil a proclamação da República que aconteceu no ano de 1889. Luiz Simas (2019) associa este evento ao dia nacional da Umbanda, afirmando que o surgimento dessa religião nas primeiras décadas da República reflete a construção de uma identidade nacional. Neste sentido, o Caboclo das 7 Encruzilhadas, chamo assim porque não teriam caminhos fechados para ele, e Zélio narram a história brasileira com todo seu tensionamento e atualidade.

Há um país oficial que ainda tenta silenciar os índios, os caboclos, os pretos, os ciganos, as pombagiras (mulheres donas do próprio corpo em encanto) e todos aqueles vistos como estranhos por um projeto colonial amansador de corpos, disciplinador de condutas e aniquilador de saberes (SIMAS, 2019, p.171).

Zélio Fernandino e outros dirigentes umbandistas fundaram, em 1939, a primeira Federação de Umbanda do Rio de Janeiro, a União Espírita da Umbanda no Brasil, 
baseada nas associações kardecistas que existiam na época (MORAIS, 2010). Buscaram racionalizar mitos e ritos da Umbanda e, assim como os kardecistas, procuravam associar estes a teses científicas. Foi publicada uma série de obras de intelectuais de Umbanda, fazendo com que os ensinamentos passassem também a ser difundidos de forma escrita. A Umbanda vira a "Religião do Livro" e não apenas uma 'Religião da Palavra" como outros cultos afro-brasileiros (QUEIROZ, 1989). Na década de 1960, mais de 400 obras foram publicadas, com temas que variavam desde explicações sobre a origem da Umbanda a explicações sobre o processo ritual e suas entidades (MORAIS, 2010).

Em 1941, foi realizado no Rio de Janeiro, pelas Federações Umbandistas da época, o Primeiro Congresso de Espiritismo de Umbanda e neste predominou a defesa de que a origem da Umbanda estaria atrelada as tradições místicas orientais (GIUMBELLI, 2002). Para muitos dos chamados intelectuais de Umbanda, a palavra "Umbanda” seria originária do sânscrito: “o prefixo 'aum' está ligado à magia e é considerado sagrado por mestres orientalistas" (MORAIS, p. 44, 2010). Os anais do evento, citados por Ortiz (1978, p.151), atestam esta origem antiquíssima da religião:

Sabendo-se que os antigos povos africanos tiveram sua época de dominação além-mar, tendo ocupado durante séculos uma grande parte do oceano Índico, onde uma lenda nos diz que existiu o continente perdido da Lemúria, do qual a Austrália, a Australásia e as ilhas do Pacífico constituem as porções sobreviventes, - fácil nos será concluir que a Umbanda foi por eles trazida ao seu contato com os povos hindus, com os quais aprenderam e praticaram durante séculos. E, assim deve ser, decerto, a nossa concepção do Espiritismo de Umbanda.

Umbanda não é um conjunto de fetiches, seitas ou crenças, originárias de povos incultos, ou aparentemente ignorantes; Umbanda é, demonstradamente, uma das maiores correntes do pensamento humano existentes na terra há mais de cem séculos, cuja raiz se perde na profundidade insondável das mais antigas filosofias.

Vinte anos mais tarde, em um Segundo Congresso de Umbanda, um movimento liderado por Tancredo da Silva Pinto, que também escreveu uma série de livros, considerava que a Umbanda tinha origem africana: "'o termo seria oriundo de uma tribo banta, os lundas-quioco, situados no Sul de Angola' (MORAIS, 2010, p.45). Tata Tancredo, em 1950, e a Confederação Espírita Umbandista do Brasil afirmava que "terreiro de umbanda que não utiliza tambor nem canta pontos no idioma africano e, também, não oferece preceitos com o sacrifício de animais, 'pode ser tudo, menos terreiro de Umbanda" " (OLIVEIRA, 2017, p.113). 


\section{Umbanda Esotérica}

Woodrow Wilson da Matta e Silva, conhecido como mestre Yapacani ou Pai Matta, é o grande nome da Umbanda Esotérica e é considerado o criador da primeira escola iniciática da Corrente Astral do Aumbhandan. Suas ideias são análogas aquelas defendidas no Primeiro Congresso Espiritismo de Umbanda de 1941. Nasceu em Garanhuns, Pernambuco em 28 de julho de 1917 (OLIVEIRA, 2017).

A hipótese mais provável é que tenha chegado à então capital da República (Rio de Janeiro) na adolescência, no início dos anos trinta, juntando-se às levas de nordestinos que desde meados do século XIX ocupavam a região central da cidade"' (OLIVEIRA, 2017, p.95).

Afirmava ter diversas visões desde a infância e, na adolescência, incorporou pela primeira vez o Preto Velho Pai Guiné da Angola que se apresentou inicialmente como Pai Cândido. A partir de então, começou a prestar consulta às pessoas juntamente com a entidade que o assistia, sendo proibido pelo guia de frequentar qualquer tipo de centro ou terreiro. A entidade comunicou que daria todas as instruções em relação à tarefa que o astral havia lhe conferido e que no futuro ele escreveria livros importantes. No bairro da Pavuna no Rio de Janeiro, fundou seu primeiro terreiro, a Tenda Umbandista Oriental - TUO, que esteve ativa por 20 anos e encerrou seus trabalhos em 1958 quando Matta decidiu realizar mudanças doutrinárias e praticar a Umbanda Esotérica (OLIVEIRA, 2017). Após o fechamento do primeiro terreiro, Matta e Silva, no município de Itacuruçá no Rio de Janeiro, reabre a Tenda Umbandista Oriental. Em Itacuruçá, Matta criou um sistema de iniciação que é entendido como uma forma de administrar o conhecimento, sendo que as pessoas passariam por transformações físicas e de sua própria mediunidade.

Matta escreveu nove livros: Mistérios e Práticas da Lei de Umbanda, Lições de Umbanda e Quimbanda na palavra de um Preto-Velho, Segredos de Magia de Umbanda e Quimbanda, Umbanda e o Poder da Mediunidade, Umbanda de Todos Nós, Umbanda Sua Eterna Doutrina, Doutrina Secreta de Umbanda, Umbanda do Brasil, Macumbas e Candomblés na Umbanda. Esses são livros caros aos estudos dos médiuns do TUÉS e que são recomendados como manuais para se entender como se funciona a "verdadeira" umbanda. Matta buscou inspiração em obras etnográficas do século XX 
para escrever seus livros e faz menção a famosos antropólogos da época. Sobre isso Oliveira (2017) comenta que:

Leu desde Nina Rodrigues a Roger Bastide, passando pelos estudos de Manoel Querino, Waldemar Bento, Donald Pierson, Gilberto Freire, entre outros africanistas e antropólogos... O escritor, contudo, não hesitou em colocar no mesmo nível de importância tanto a produção acadêmica sobre as religiões de matriz africana, quanto os estudos de Fabre D'Olivet, Saint-Yves d'Alveydre, Édouard Schuré, Gérard Anaclet Encausse (Papus) entre outros, sobre a origem da humanidade e das religiões (OLIVEIRA, 2017, p.105).

Matta e Silva foi um pensador de seu tempo, profundamente influenciado pelas teorias raciais e pelo evolucionismo social que marcou os intelectuais brasileiros das primeiras décadas do século $\mathrm{XX}$. Tanto que os estudos sobre as heranças africanas no Brasil disponíveis na época contribuíram para construir a ideia de que a umbanda teria uma origem mais nobre do que um mero desdobramento dos cultos afro-brasileiros (OLIVEIRA, 2017, p.106).

Matta afirmava que a palavra Umbanda ou Aumbhandan, que para o autor significa Conjunto das Leis de Deus, possuía origem em uma língua antiquíssima e universal, o Alfabeto Adâmico ou Vattan, que teria íntima relação com a origem do sânscrito e com a Lei de Pemba ou Escrita Sagrada dos Orixás na Umbanda Esotérica. Essa tese confirma a profunda influência que o ocultista francês Saint-Yves D'Alveydre exerceu em suas obras. Para o ocultista, o alfabeto seria composto de um ponto, de uma linha, da circunferência, do triangulo equilátero e do quadrado, conhecido como Vattan para os brâmanes (OLIVEIRA, 2017). Segundo Luís Gustavo, dirigente do TUÉS, essa é a base de qualquer ponto riscado: o ponto, a reta e o círculo.

É comum em suas prédicas o chefe do terreiro fazer referência ao Bhagavad Gita $^{5}$ dos hindus e a outras doutrinas como o taoísmo, por exemplo. Certa vez explicou que o termo Exu, que significa "aquele que foi exilado" ou "exudado", derivava do episódio de dissolução do princípio espiritual puro, o Cisma de $\mathrm{Irshu}^{6}$, que está relatado no BhagavadGita. Em um rito dedicado às Pombagiras, no ano de 2016, momentos antes de liberar a entrada dos consulentes no terreiro, Luís Gustavo nos mostrou um ponto riscado inscrito em uma tábua quadrada de madeira. O sacerdote disse que o

\footnotetext{
${ }^{5}$ Este é um texto contido no livro Mahabarata que narra um diálogo entre Krishna, a entidade suprema do Universo para os hindus, e Arjuna, um príncipe. Carrega os princípios que regem os conhecimentos védicos.

${ }^{6}$ Entende-se no TUÉS que o Cisma de Irshu ou Erxu é o que deu origem ao nome da entidade Exu que significa "aquele que foi exilado", "Exudado". Irshu é o nome de príncipe indiano filho de um imperador chamado Urga. O príncipe defendia o princípio natural (material ou feminino) e o imperador defendia princípio espiritual (masculino), havendo uma separação e um novo cisma.
} 
ponto estava escrito em sânscrito e que essa língua estava intimamente ligada ao Cisma de Irshu que representa o conflito entre solares e lunares ${ }^{7}$.

Nas tradições esotéricas, o conhecimento não tem caráter democrático. Pode ser dividido em dois tipos: o conhecimento exotérico, com ' $\mathrm{x}$ ', e o conhecimento esotérico, com 's' (MATTA E SILVA, 2003). O primeiro está relacionado com o conhecimento público e da própria ciência acadêmica. O segundo corresponde aos conhecimentos integrais ou iniciáticos. A primeira dimensão da iniciação (os quatro primeiros graus de iniciação), desenvolvida por Matta e adotada no TUÉS, se relaciona com quatro pilares do conhecimento: filosofia, religião, artes e ciência. O quinto grau tem a ver com a integração dos conhecimentos, ou seja, a Proto-Síntese Religio-Cientifica. O sexto grau se relaciona ao amor cósmico e o sétimo grau à sabedoria cósmica. A segunda dimensão da iniciação (sexto e sétimo grau), portanto, envolve a Proto-Sintese Cósmica que seria a ciência das ciências. O Aumbandan é considerado a síntese de todo o conhecimento humano (Neto, 2007).

A ciência, para além de ser um dos pilares do conhecimento iniciático, está presente, pelo menos em discurso, como parte da explicação de diversos fenômenos existentes no terreiro. Senhor Corcunda, $E x u^{8}$ chefe do terreiro, em um rito interno em 2018 (rito exclusivo para os médiuns da casa), comentou que a espiritualidade não tem a ver com misticismo ou fantasia. Ela se relacionaria mais com a ciência do que poderíamos supor. Outro caso que exemplifica a íntima relação entre o discurso religioso e o cientifico ocorreu quando a médium Carolina perguntou ao sacerdote do terreiro, Luís Gustavo, se era comum sentir dores de cabeça após os ritos e ele explicou que:

é normal dor de cabeça pelo uso de plasma do sangue para as atividades espirituais, trata-se de uma desidratação das células do cérebro, que deve ser reposto com muita água e água de coco, fora a utilização de proteína animal para carregar a célula com ATP

\footnotetext{
${ }^{7}$ Segundo os membros do terreiro, solares são aqueles que entendem Deus como dual, feminino e masculino e cultuam o princípio espiritual representado pelo sol. Os lunares, na visão destes umbandistas, entendem Deus a partir de uma perspectiva em que estes polos, feminino e masculino, estão desconectados. Existe um Deus e uma Deusa. Os lunares cultuam a lua, energia feminina e o princípio material. Um exemplo de culto atual que é considerado lunar por estes umbandistas é a Wicca. Essa cisão entre solares e lunares, para os umbandistas esotéricos, aconteceu repetidas vezes ao longo da história, como é o caso do Cisma Tupi, do Cisma Atlântico e do Cisma de Irshu - que está relatado no Bhavad Guita, o livro sagrado dos hindus. Essas disputas entre lunares e solares são responsáveis pela fragmentação do conhecimento uno ou Aumbhandhan, fazendo com que a Umbanda seja conhecida como o elo perdido (Neto, 1990)).

${ }^{8}$ Falange ou grupamento de espíritos comparáveis à polícia do astral segundo frequentadores do TUÉS. São responsáveis pela segurança dos ritos e considerados com executores das Leis Divinas, não sendo bons nem maus, mas justos.
} 
produzida pelas mitocôndrias e repor a perda de ectoplasma. (Luís Gustavo, Templo Universalista e Espiritualista Solar, Jul.2017)

Em outros momentos, argumentos com caráter científico ou de linguagem próxima à da ciência foram acionados para explicar questões rituais relativas à Umbanda. A gargalhada de exu, por exemplo, é entendida como um instrumento de trabalho: seu som consegue interagir com os campos energéticos dos seres humanos, não sendo essa apenas uma forma de deboche ou escárnio como muitos acreditariam. Os banhos de sal grosso são recomendados, porque, segundo os membros do TUÉS, a água transforma o sal em íons e este em contato com a pele restabeleceria o equilíbrio energético do indivíduo. Há, neste sentido, um borramento da fronteira presente entre as explicações mágicas, científicas e religiosas.

Ao mesmo tempo, há um reconhecimento de que a ciência baseada em preceitos iluministas modernos não dá conta da espiritualidade, mesmo que no futuro esses fenômenos possam ser entendidos cientificamente. Sr. Corcunda, em um rito público, falou ironicamente para os consulentes que queria ver um cientista pegar um charuto e a bebida e ficar $4 \mathrm{~h}$ incorporado "fingindo". O guia, em tom desafiador, afirmou que daria conta de fazer ciência, porque tem conhecimentos neste campo, mas que o cientista não conseguiria fazer a ciência que ele faz. Segundo Simas, Rufino (2018):

A macumba é ciência, é ciência encantada e amarração de múltiplos saberes. É assim que ela é versada no segredo da jurema, dos catimbós, torés, babaçuês e encantarias. Não somos nós que dizemos; as falas são dos mestres ajuremados e acaboclados nas cidades encantadas e na textualidade das folhas... A perspectiva do encantamento é elemento e prática indispensável nas produções de conhecimento... Na miudeza da vida comum os saberes se encantam e são reinventados os sentidos do mundo. (SIMAS; RUFINO, 2018, p.12)

A ciência, desta forma, assim como outras religiões e religiosidades compõe a rede universalista da Umbanda Esotérica, ganhando status de uma de suas linhas e sendo afetada e modificada por esta religiosidade afro-indígena. Esta possui uma polissemia por abranger desde a ciência acadêmica, a ciência oculta até vertentes menos consagradas nos meios acadêmicos como a parapsicologia, quirologia, homeopatia, fitoterapia. Segundo Otávio, membro do TUÉS:

A Proto-Síntese Religio-Científica é o processo de você racionalizar todos os fenômenos paranormais, racionalizar todos os fenômenos espiritualizados, racionalizar os milagres e ver que tudo isso é uma 
ciência. Ou a ciência da química quântica ou uma ciência da física quântica ou ciência metafísica ou parapsicologia e associar, porque todo nosso conhecimento atual está fragmentado, está tudo dividido... E quando você se torna essa pessoa total, esse ser consciente e lúcido, que tem base científica, que tem base filosófica, que tem base artística e que tem base religiosa - ou da religiosidade e não da religião- você caminha (Otávio, 2017).

Segundo Luís Gustavo, “A Umbanda a nível de teologia aceita todas as teses e possibilidades de explicação do fenômeno que chamamos de espiritual, inclusive a leitura meramente científica, pois, ao contrário do que se imagina na matéria, tudo é ciência”. Dessa forma, a ciência faz parte da equação universalista e traz a questão se este é um bom ou mal encontro, por aparentemente introduzir hierarquias e valorações. Ao mesmo tempo, o próprio exu chefe do TUÉS aponta os limites da ciência quando se trata de um contexto religioso.

\section{Nova era e religiosidade afro}

A Umbanda é múltipla e apresenta diversas linhas que possuem uma distância elástica em relação ao Candomblé, ao kardecismo e a outras doutrinas religiosas, como as orientais. Assim ela nos mostra que a diferença não significa uma separação absoluta e é intrínseca à própria religiosidade afro-brasileira ou afro-indígena. Desde a sua sistematização, a partir de 1930, a ciência e teses sobre a origem antiquíssima da Umbanda permeavam os discursos e as obras de muitas vertentes umbandistas, principalmente aquela resultante de Zélio Fernandino de Morais. Sobre isso Bastide (2006, p. 225-226) comenta que: "Eles leram muito, os livros esotéricos de Annie Besant, dos espíritas de Allan Kardec até os livros dos antropólogos e dos africanistas”.

A Umbanda Esotérica surge em meados de 1956 no mesmo contexto do movimento Nova Era (anos 60 e 70), a contracultura e um fluxo crescente de intercâmbio entre Oriente e Ocidente. No Brasil, a Nova Era ganha um aspecto singular, atingindo também camadas mais populares e a cultura dos espíritos existente no país (AUBRÉE; LAPLANTINE, 2009). Segundo Oliveira (2014), existiria uma "Nova Era Brasileira", articulando elementos da religiosidade afro. Dessa forma, Amaral (2000, p.15) considera a Nova Era da seguinte forma:

Trata-se, assim, de um fenômeno heterogêneo e não se apresenta como um movimento organizado. A este fenômeno estarei me referindo com a expressão Nova Era, focalizando-o como um campo de discursos variados, mas em cruzamento, por onde passam: a) os 
herdeiros da contracultura com suas propostas de comunidades alternativas; b) o discurso de autodesenvolvimento, na base das propostas terapêuticas atraídas por experiências místicas e filosofias holistas, fazendo-as corresponder às modernas teses de divulgação científica; c) os curiosos do culto, informados pelos movimentos esotéricos do século XIX e pelo encontro com as religiões orientais, populares e indígenas;

Ao mesmo tempo, afirmar que a Umbanda Esotérica seja constituinte da Nova Era não pode desconsiderar ou não levar a sério como os próprios membros do TUÉS entendem a sua prática e doutrina religiosa. Para o grupo, a Umbanda e sua vertente esotérica são religiosidades que incluem em sua narrativa cosmológica sociedades antiquíssimas com uma história tão antiga quanto se possa conceber. Dessa forma, nesta percepção, a Umbanda tem de fato milhares de anos e guarda segredos universais, sendo conhecida como Senhora da Luz Velada.

A ciência, que esteve no cerne da reforma da Umbanda na década de 1930, para nos valermos de um termo moldado por Ordep Serra, sendo utilizada por empreitadas positivistas e embranquecedoras, também foi afetada por este encontro e foi apropriada a seu modo pelos umbandistas esotéricos.

O Universalismo, que para esses umbandistas é um signo da Nova Era, não é algo narcísico, mas que acolhe e se torna múltiplo. Há a diferença de um Deus sem imagem e que não está a procura de um espelho para um Deus, que, em um outro sentido do universal, desterritorializa o outro para que se possa fazer parte.

\section{Referências Bibliográficas}

AMARAL, L. Carnaval da Alma: comunidade, essência e sincretismo na nova era. Petrópolis: Vozes, 2000.

AUBRÉE, M.; LAPLANTINE, F. A Mesa, o Livro e os Espíritos. Maceió: Edufal, 2009.

BANNAGIA, G. Inovações e Controvérsias na Antropologia das Religiões Afrobrasileiras. 2008. 227 f. Dissertação (Mestrado em Antropologia Social) - Programa de Pós-Graduação em Antropologia Social, Museu Nacional da Universidade Federal do Rio de Janeiro, Rio de Janeiro, 2008.

BASTIDE, R. Estudos Afro-Brasileiros. São Paulo: Perspectiva, 1973. 
BASTIDE, R. O Sagrado Selvagem e Outros Ensaios. São Paulo: Companhia das Letras, 2006.

CAPRA, F. O Ponto de Mutação. São Paulo/SP: Editora Cultrix, 1982.

CAPRA, F. The Tao of Physics: an exploration of the parallels between modern physics and eastern mysticism. California: Shambhala Publications, 1975.

CORDOVIL, D.; CASTRO, L. S. dos S. de. "Espíritos de Índios na Umbanda Esotérica: uma complexa teia de representações". PLURA, Revista de Estudos de Religião, vol. 9, n 1, 2018, p. 167-187.

CUNHA, M. C. Antropologia do Brasil. São Paulo: Brasiliense/EDUSP, 1987.

FLAKSMAN, C. "Enredo de Santo e Sincretismos no Candomblé de Salvador, Bahia". Revistade@ntropologiada UFSCar,v.9, n.2, jul./dez. 2017.

GIUMBELLI, E. "Zélio de Moraes e as Origens da Umbanda no Rio de Janeiro". In: SILVA, V. G. (org.): Caminhos da Alma: memória afro-brasileira. São Paulo: Summus, 2002.

GOLDMAN, M. "Histórias, Devires e Fetiches das Religiões Afro-brasileiras: ensaio de simetrização antropológica”. Análise social, vol. XLIII, n.190, 2009, p.105 - 137.

GUERRIERO, S. Novos Movimentos Religiosos: o quadro brasileiro. 1.ed. São Paulo: Paulinas, 2006.

JORGE, É. F. C.; RIVAS, M. E. G. B. M.; CARNEIRO, J. L. A. “O Espaço da Mulher nas Fases da Umbanda Esotérica”. Religare, v.13, n.1, julho de 2016, p.49-63.

MAGNANI, J. G. C. O Brasil da Nova Era. Rio de Janeiro: Jorge Zahar Ed., 2000.

MATTA E SILVA, W. W. Umbanda e o Poder da Mediunidade. São Paulo: Ícone, 2003.

MORAIS, M. R. Nas Teias do Sagrado: registros da religiosidade afro-brasileira em Belo Horizonte. Belo Horizonte: Espaço Ampliar, 2010.

NETO, F. R. Umbanda: proto-síntese cósmica. $4^{\mathrm{a}}$ ed. São Paulo: Pensamento, 2007.

OLIVEIRA, A. P. "Nova Era à Brasileira: a new age popular do Vale do Amanhecer". INTERAÇÕES - Cultura e Comunidade, v. 4, n. 5, 2009, p. 31-50. Disponível em:

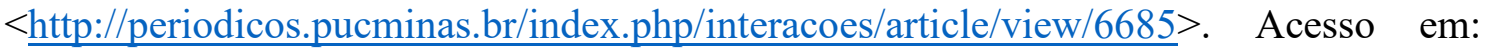
set.2018.

OLIVEIRA, A. P. “A Nova Era com Axé: umbanda esotérica e esoterismo umbandista no Brasil". R. Pós Ci. Soc. v.11, n.21, jan/jun. 2014. 
OLIVEIRA, J. H. M. A Escrita do Sagrado na Literatura Umbandista: uma análise da obra de Matta e Silva em perspectiva comparada. Tese de Doutorado - Programa de Pós-graduação em História Comparada, Instituto de História, Universidade Federal do Rio de Janeiro. Rio de Janeiro: 2017.

ORTIZ, R. A Morte Branca do Feiticeiro Negro - Umbanda: integração de uma religião numa sociedade de classe. Petrópolis: Editora Vozes, 1978.

PRANDI, R. Os candomblés de São Paulo. São Paulo: Hucitec, 1991.

QUEIROZ, M. I. P. "Identidade Cultural, Identidade Nacional no Brasil". Revista Tempo Social, v.1, n.1, 1989.

SEGATO, R. L. "Um Paradoxo do Relativismo: o discurso racional da antropologia frente ao sagrado". Religião e Sociedade, v.16, n.1/2, 1992, p.114-135.

SERRA, O. Águas do Rei. Petrópolis: Editora Vozes, 1995.

SERRA, O. Os Olhos Negros do Brasil. Salvador: Ed. UFBA, 2014.

SIMAS, L. A. O corpo encantado das ruas. Rio de Janeiro: Civilização Brasileira, 2019.

SIMAS, L. A.; RUFINO, L. Fogo no Mato: a ciência encantada das macumbas. 1. Ed. Rio de Janeiro: Mórula, 2018.

STENGERS, I. "A Proposição Cosmopolítica". Revista do Instituto de Estudos Brasileiros Brasil, n. 69, p. 442-464, abr. 2018.

STRATHERN, Marilyn. O efeito etnográfico e outros ensaios. São Paulo: Cosac Naify, 2014.

VERAS, H. S. “A intolerância e o Pluralismo Religioso sob a Ótica Ritual Afrobrasileira”. In: TADVALD, M. (Org.). Religião e sociedade: estudos, trajetórias e desafios. Porto Alegre: Casa Verde, 2018.

Recebido em: 15/10/2019

Aceito em: 23/10/2019 